\title{
A construção argumentativa do dizer do aluno na produção textual escrita no ensino médio*
}

\section{The argumentative construction of students' saying in writing practices in middle school}

\author{
Joseilda Alves de Oliveira ${ }^{1}$ \\ José Cezinaldo Rocha Bessa ${ }^{2}$
}

\begin{abstract}
Resumo: O propósito deste artigo é apresentar resultados de uma intervenção didática voltada ao aprimoramento da capacidade argumentativa de alunos de uma turma de $1^{\circ}$ ano do ensino médio de uma escola pública. No recorte feito aqui, o foco da análise se concentra na construção argumentativa do dizer de um desses alunos, considerando o cotejo de suas produções escritas, antes e depois do trabalho interventivo. Tomando como respaldo teórico-metodológico basilar ideias sobre o funcionamento dialógico da linguagem do Círculo de Bakhtin (BAKHTIN, 2011; 2016; 2016; VOLÓCHINOV, 2017) e contribuições da Nova Retórica de Perelman e OlbrechtsTyteca (2014) acerca da argumentação no discurso, este trabalho examina dois textos (uma redação escolar, produzida antes da intervenção, e uma carta do leitor produzida no final da intervenção) de um mesmo aluno/produtor. $\mathrm{O}$ estudo empreendido reforça a importância da atividade interventiva realizada como proposta de trabalho capaz de potencializar a capacidade argumentativa do aluno na produção de textos em sala de aula da educação básica.
\end{abstract}

Palavras-chave: Argumentação. Ensino Médio. Carta do leitor. Círculo de Bakhtin. Nova Retórica.

\begin{abstract}
The purpose of this article is to present the results of a didactic intervention aimed at improving the argumentative capacity of students in a 1st year middle school class of a public school. The research focus of the analysis focuses on the argumentative construction of the saying of one of these students, considering the comparison of their written productions, before and after the intervention work. Taking as theoretical-methodological support basic ideas on the dialogical functioning of the language of the so-called Bakhtin Circle (BAKHTIN, 2011; 2016; 2016; VOLÓCHINOV, 2017) and contributions of Perelman and Olbrechts-Tyteca's New Rhetoric (2014) about discourse argumentation, this paper examines two texts (a school essay, produced before the intervention, and a letter from the reader produced at the end of the intervention) from the same student/producer. The study reinforce the importance of the interventional activity performed with the letter reader genre as a work proposal capable of enhancing the student's argumentative capacity in the production of texts in the basic education classroom.
\end{abstract}

Keywords: Argumentation. High school. Reader's letter. Bakhtin Circle. New Rhetoric.

\footnotetext{
* Este trabalho apresenta um recorte, com modificações, revisões e acréscimos, da dissertação de mestrado intitulada Produção textual argumentativa na sala de aula: do editorial à carta do leitor (OLIVEIRA, 2019).

${ }^{1}$ Universidade do Estado do Rio Grande do Norte, Programa de Pós-Graduação em Letras, Pau dos Ferros, RN, Brasil. Endereço eletrônico: joshitalo@gmail.com.

${ }^{2}$ Universidade do Estado do Rio Grande do Norte, Programa de Pós-Graduação em Letras, Pau dos Ferros, RN, Brasil. Endereço eletrônico: cezinaldobessa@uern.br.
} 


\section{Introdução}

Dados do Instituto Nacional de Estudos e Pesquisas Educacionais Anísio Teixeira (INEP) apontam que, em 2019, 143,7 mil estudantes obtiveram nota zero na redação do ENEM, o que correspondeu a $4 \%$ dos candidatos inscritos, percentual superior ao de 2018 , quando $2,7 \%$ dos participantes haviam tirado nota zero. Nas redações com nota zero, no ano de $2019,42 \%$ se deram porque os candidatos entregaram a prova em branco, $28 \%$ porque fugiram ao tema e $16 \%$ por causa de cópia dos textos motivadores. Embora o percentual de candidatos com nota zero se mostra relativamente baixo (4\%), podemos perceber que, em números absolutos, o quantitativo de candidatos com notas zero se aproxima de 150 mil candidatos, indicando, em certa medida, um desempenho preocupante.

Esses dados, assim como inúmeras pesquisas e reflexões da área (ANTUNES, 2003; 2009; LOPES-ROSSI, 2008; NASCIMENTO, 2010; MORETTO， 2013; KERSCH; MARQUES, 2017; MENDONÇA, 2019; DANTAS; LIMA, 2019; dentre outras), sinalizam que, apesar dos avanços nas propostas metodológicas e tecnologias digitais na educação (COSCARELLI, 2019; RIBEIRO, 2018, 2020), temos ainda muitos desafios a serem enfrentados em relação ao trabalho com a produção textual na educação básica. Dentre esses desafios, encontra-se conceber, elaborar e implementar propostas de produção textual voltadas não para atender apenas a situação específica de escrita do Exame Nacional do Ensino Médio (ENEM), mas também, e sobretudo, com vistas a melhor preparar o aluno para a diversidade de práticas sociais nas quais os usos da linguagem estão inevitavelmente implicados.

Foi pensando na direção apontada acima que, em nossa pesquisa de mestrado na área de ensino de línguas (OLIVEIRA, 2019), procuramos desenvolver uma proposta de intervenção com a finalidade de trabalharmos a produção textual em sala de aula do ensino médio. Nosso intuito foi trabalhar em uma perspectiva que buscasse desenvolver a capacidade argumentativa dos alunos, articulada às formas de manifestação dialógica da linguagem, a partir de uma abordagem centrada nos gêneros do discurso.

O enfoque na abordagem da produção textual centrada na construção argumentativa do dizer do aluno mostra-se um empreendimento cada vez mais pertinente e necessário em nossos dias. Isso porque compreendemos que, para produzir textos argumentativamente consistentes e adequados aos propósitos comunicativos, é fundamental um trabalho que, dentre outras possibilidades, possa articular aspectos da argumentação às formas de manifestação das palavras de outrem como estratégia textual e discursiva constitutiva de todo o dizer. O enfoque assumido nessa proposta representa, portanto, uma perspectiva de trabalho que vai além das fórmulas e dos modelos prontos, tão conhecidos e criticados por estudiosos. 
Assim, objetivamos, com este trabalho, apresentar resultados de uma intervenção didática voltada ao aprimoramento da capacidade argumentativa de alunos de uma turma de $1^{\circ}$ ano do ensino médio de uma escola pública. No recorte trazido aqui e dada a ancoragem em princípios teórico-metodológicos dos estudos bakhtinianos, o foco da análise se concentra na construção argumentativa do dizer de um desses alunos, considerando o cotejo de suas produções escritas, antes e depois do trabalho interventivo.

Entendemos que um trabalho como esse, que se soma a diversas investigações (NASCIMENTO; CARVALHO, 2015; AZEVEDO, 2016; dentre outras) centradas na potencialização da construção argumentativa na produção de textos escritos em aulas de Língua Portuguesa, pode contribuir com um ensino de produção textual produtivo e adequado às exigências de uma formação mais sólida que favoreça o desenvolvimento de posicionamentos críticos. Acreditamos, além disso, que essa proposta de trabalho pode contribuir para promover uma participação social mais ativa dos alunos no mundo da vida, sobretudo nesses tempos de circulação de textos fakes, ideias fracionadas e de reprodução de conteúdos e informações.

Para darmos conta da proposta de pesquisa delineada aqui, este artigo apresenta, em sua arquitetura textual, a seguinte organização: além desta introdução, o texto traz uma seção teórica, na qual discutimos pressupostos teóricos centrais (da abordagem dialógica da linguagem bakhtiniana e da argumentação no discurso da Nova Retórica) que ancoram nossa investigação; em seguida, descrevemos a metodologia empregada; depois, trazemos a análise da construção argumentativa nas produções selecionadas para exame; e, por fim, apontamos nossas considerações finais.

\section{Ancoragem teórica}

Nesta seção do trabalho, apresentamos uma síntese dos pressupostos teóricos centrais que ancoram a nossa análise. Nesse sentido, focalizamos, inicialmente, a concepção bakhtiniana de linguagem; em seguida, reportamo-nos à abordagem da Nova Retórica sobre argumentação no discurso, e, por fim, tratamos do gênero discursivo carta do leitor. Cumpre destacarmos que a opção por abordar a carta do leitor se justifica pelo fato de se tratar do gênero que solicitamos para a produção dos alunos no decorrer da proposta de intervenção realizada.

\section{A constituição dialógica do dizer na perspectiva do pensamento bakhtiniano}

Dentre as contribuições do pensamento bakhtiniano para os estudos da linguagem está a possibilidade de construirmos uma compreensão mais profunda sobre texto/discurso e seu ensino, fundamentada no princípio dialógico da linguagem. Numa perspectiva de estudos nessa 
direção é essencial, antes de tudo, entendermos como o pensamento do Círculo de Bakhtin concebe o dialogismo, dada a importância desse conceito na construção de um modo diferente de entender o funcionamento da linguagem. De acordo com esse modo de pensar, as relações dialógicas são o centro de interesse do estudo da linguagem, pois pertencem ao campo do discurso, o qual pressupõe que o funcionamento concreto da linguagem resulta da interação entre fatores linguísticos e extralinguísticos.

É bem verdade que, em Bakhtin, a concepção de dialogismo se mostra mais ampla e complexa, remetendo à própria condição humana (BESSA, 2016). Nas palavras de Bakhtin (2011, p. 348), "nesse diálogo o homem participa inteiro e com toda a vida: com os olhos, os lábios, as mãos, a alma, o espírito, todo o corpo, os atos.”. Entende-se, nessa perspectiva, o homem como um ser que participa, atua, responde e, por isso, dialógico continuamente, em todos os momentos, num processo de constituição pelo diálogo, pela própria relação com o outro.

Pensando a linguagem, mais especificamente, como manifestação dialógica, assume-se que, na atividade interativa humana, não há um primeiro enunciado e nem um último, porque, entendendo a partir de Bakhtin (2015), todas as orientações do discurso se encontram com a palavra do outro e, de maneira inevitável, entram em uma interação viva e tensa de vozes sociais. O encontro com a palavra do outro é lugar de construção de sentidos, de construção dos enunciados. "Evidentemente, o enunciado se forma entre dois indivíduos socialmente organizados" (VOLOCHINOV, 2017, p. 204), é um ato inseparável do acontecimento de comunicação. Além de se constituir na atmosfera do já-dito, o enunciado, em sua singularidade e concretude, se forma contando com atitudes responsivas do interlocutor, ainda que este não esteja fisicamente presente, participando da situação imediata de interlocução. Em outras palavras, todo enunciado está voltado para uma reação resposta: “é como se todo o enunciado se construísse ao encontro dessa resposta" (BAKHTIN, 2016, p. 62).

O papel do outro como respondente ativo no processo de constituição do enunciado é algo indiscutível. Certamente, não há, por exemplo, como produzir enunciado sem a participação do interlocutor para quem nos dirigimos: "esses outros, para os quais o meu pensamento real (e deste modo também para mim mesmo), não são ouvintes passivos, mas participantes ativos da comunicação discursiva” (BAKHTIN, 2016, p. 62). O endereçamento é, portanto, um traço imprescindível na constituição do enunciado. É no discurso (resposta) do outro que acontece a construção dialógica, que nenhum assunto simplesmente centralizado no objeto pode causar (BAKHTIN, 2016). A comunicação, nessa direção de pensamento, encontra-se no embate, na relação dialógica do enunciado com o interlocutor. 
Nesse sentido, nossa compreensão do funcionamento dialógico da linguagem precisa considerar a complexidade da constituição dos enunciados na interação com a palavra de outrem, bem como sua produção, circulação e recepção nas diversas esferas da atividade humana, conforme indica Bakhtin (2016).

Para compreendermos o enunciado, precisamos considerar elementos além dos meramente linguísticos, ou seja, a dimensão restrita dos aspectos gramaticais e abstratos não dá conta de abarcar o enunciado, já que os sentidos se produzem na relação entre uma parte verbal e uma parte extraverbal, o que significa dizer que os sentidos possíveis de um determinado enunciado vão além do significado que o material linguístico é capaz de expressar. Volóchinov (2017) nos orienta nessa linha de compreensão quando diz: “a situação social mais próxima e o ambiente social mais amplo determinam completamente e, por assim dizer, de dentro, a estrutura do enunciado" (VOLÓCHINOV, 2017, p. 206, grifos do autor).

Entendemos, assim, que a situação constrói, forma e elabora o enunciado, seja de um modo ou de outro: "Antes de mais nada, ele é determinado de modo mais próximo pelos participantes do enunciado, tanto os imediatos quanto os distantes, e em relação a uma situação determinada, isto é, a situação forma o enunciado, obrigando-o a soar de um modo e não de outro" (VOLÓCHINOV, 2017, p. 206). Nessa perspectiva, podemos considerar que, diferentemente da oração como unidade do sistema linguístico, o enunciado é da ordem do irrepetível, do não suscetível à mera reprodução mecânica. Para Volóchinov (2017, p. 310), “cada texto (como enunciado) é algo individual, único e singular, e nisso reside todo seu sentido (sua intenção em prol da qual ele foi criado)".

Ainda em relação ao caráter irrepetível do enunciado, o autor afirma que o sentido do enunciado "é aquilo que nele tem relação com a verdade, com a bondade, com a beleza, com a história" (VOLÓCHINOV, 2017, p. 310). Assim sendo, em certa medida, isso extrapola os limites do que possa ser repetido ou reproduzido, pois, para Bakhtin (2016, p. 103, grifos do autor), “o enunciado pleno já não é uma unidade da língua, [...] mas uma unidade de comunicação discursiva, que não tem significado, mas sentido”.

No pensamento bakhtiniano, podemos dizer, portanto, que o enunciado adquire sentido na cadeia da comunicação discursiva, em condições concretas de uso e como resultado do embate dialógico e ideológico com enunciados anteriores e posteriores, surgindo num determinado momento histórico e em um contexto social específico. O enunciado, para Bakhtin (2015, p. 49), "não pode deixar de tocar milhares de linhas dialógicas vivas envoltas pela consciência socioideológica no entorno de um dado objeto da enunciação", concretizando-se, pois, todo dizer como um elo na cadeia da comunicação discursiva. 
Além de retomarmos a discussão sobre a concepção dialógica do dizer com base em reflexões do Círculo de Bakhtin sobre o funcionamento dialógico da linguagem, como fizemos neste tópico, nosso interesse em analisar a construção argumentativa do dizer do aluno implica um movimento de diálogo com a abordagem da Nova Retórica sobre argumentação no discurso. Nesse sentido, realizamos, a seguir, uma breve discussão sobre alguns dos pressupostos teóricos centrais desta abordagem.

\section{Argumentação no discurso na perspectiva da Nova Retórica}

Situados no campo dos estudos da Nova Retórica, Perelman e Olbrechts-Tyteca (2014) discutem sobre a argumentação no discurso entendendo o processo de argumentar como prática social. Desse ponto de vista, os autores assumem que "a linguagem não é somente meio de comunicação, é também instrumento de ação sobre as mentes, meio de persuasão" (PERELMAN; OLBSTRECTS-TYTECA, 2014, p. 149-150), apontando para o entendimento de que a argumentação está presente em toda e qualquer atividade discursiva.

A argumentação, nas palavras de Souza (2008), está presente no discurso de forma indissociável, compreendendo os aspectos sócio históricos e discursivos que se estabelecem na concretização das ideias elaboradas pelos interlocutores em seus processos de interação comunicativa. Em vista disso, a argumentação pode ser considerada uma característica da linguagem, independentemente da situação de comunicação, sendo inerente a qualquer gênero discursivo. Como aponta Fiorin (2016, p. 29):

Na medida em que um discurso é sempre um discurso sobre outro discurso, todos os discursos são argumentativos, pois todos eles fazem parte de uma controvérsia, refutando, apoiando, contestando, sustentando, contradizendo um dado posicionamento.

Entendemos, assim, que o ato de argumentar pode ser considerado a forma como você se posiciona na vida, entrando em embate com os discursos alheios, já que nossos discursos são uma "reação responsiva a outros discursos" (FIORIN, 2016, p. 29). E essa reação a outros discursos acontece de forma elaborada para atingir algum propósito.

Entendemos ainda que a argumentação se faz presente em todas as situações de interação humana, pois, mesmo nas relações do cotidiano, em todas as esferas sociais, os discursos, independente da sua forma mais simples ou mais complexa, estarão a serviço do convencimento ou da persuasão. É possível admitir, claro, que alguns textos apresentam características da argumentatividade de forma mais acentuada, haja vista que são concebidos para uma comunicação cuja preocupação maior é convencer alguém. Perelman e Olbstrects- 
Tyteca (2014, p. 18) afirmam que, nesse tipo de construção argumentativa, o locutor carece de "pensar os argumentos que podem influenciar seu interlocutor, preocupar-se com ele, interessar-se por seu estado de espírito", uma vez que só assim conseguirá êxito em sua busca por influenciá-lo.

Nesses casos em que os textos são pensados com o objetivo primeiro de persuadir, a articulação na seleção dos argumentos passa a ser mais criteriosa, pois considera-se a adesão do interlocutor como aspecto central. Sob esse viés, Perelman e Olbstrects-Tyteca (2014, p. 50) afirmam que o objetivo de toda argumentação "é provocar ou aumentar a adesão dos espíritos às teses que se apresentam a seu assentimento". Por isso, os recursos retóricos articulados para a construção desses enunciados devem interessar aos interlocutores e convencê-los da posição assumida pelo locutor. Quando dizem que "a argumentação efetiva tem de conceber o auditório presumido tão próximo quanto possível da realidade" (PERELMAN; OLBSTRECTSTYTECA, 2014, p. 22), os autores enfatizam a importância de se conhecer aqueles a quem se pretende conquistar. Ou seja, o orador precisa ter o conhecimento, mais claro possível, de quem seja o interlocutor, pois, como explicam Souza (2008), as escolhas que o orador faz não são resultado de sua mera vontade, mas levam em conta o auditório ao qual o discurso se dirige.

Pensando dessa forma, argumentar é compreendido como o ato de articular um conjunto de saberes e técnicas para uma atuação comunicativa eficaz, adequada à situação de comunicação e ao auditório/interlocutor. Como alguns argumentos e técnicas argumentativas podem ser eficazes para um determinado auditório e deixar de sê-lo para outros (PERELMAN; OLBSTRECTS-TYTECA, 2014), é fundamental termos em vista as técnicas e os argumentos constitutivos dos processos argumentativos conforme propõem Perelman e Olbstrects-Tyteca (2014):

Quadro 01 - Técnicas e argumentos constitutivos da argumentação

\begin{tabular}{|l|l|}
\hline $\begin{array}{l}\text { Os argumentos quase- } \\
\text { lógicos }\end{array}$ & $\begin{array}{l}\text { Compreendem técnicas amparadas em princípios lógicos; são comparáveis a } \\
\text { raciocínios formais, lógicos ou matemáticos. Englobam regras de justiça, } \\
\text { reciprocidade, definição, contradição, incompatibilidade, de transitividade e de } \\
\text { comparação. }\end{array}$ \\
\hline $\begin{array}{l}\text { Os argumentos baseados } \\
\text { na estrutura do real }\end{array}$ & $\begin{array}{l}\text { São aqueles que estabelecem uma relação que se baseia em dados da realidade do } \\
\text { interlocutor. Compreendem ligações de sucessão, ligações de coexistência e } \\
\text { ligações simbólicas. }\end{array}$ \\
\hline $\begin{array}{l}\text { Os argumentos que } \\
\text { fundam a estrutura do } \\
\text { real }\end{array}$ & $\begin{array}{l}\text { Buscam fundamentos para estruturar o real. Usam o fundamento pelo caso } \\
\text { particular (argumentos pelo exemplo, ilustração, modelo/antimodelo), e pelo } \\
\text { raciocínio por analogia (busca esclarecer, provar a partir de uma semelhança de } \\
\text { relações). }\end{array}$ \\
\hline A dissociação das noções & $\begin{array}{l}\text { Consiste em dissociar, decompor incompatibilidades presentes na tese defendida, } \\
\text { ou seja, unifica os elementos da tese fazendo remanejamento de dados conceituais } \\
\text { que servem de fundamentos para a argumentação. }\end{array}$ \\
\hline
\end{tabular}

Fonte: Elaborado por Bessa e Oliveira (2019, p. 65). 
Não basta, porém, o orador conhecer os tipos de argumentos e as técnicas argumentativas apontadas. Para ser bem-sucedido, ele precisa conhecer o auditório ao qual pretende se dirigir. Esse auditório é determinante para ele poder definir que teses defender e que técnicas argumentativas utilizar. Afinal, conforme Perelman e Olbstrects-Tyteca (2014, p. 21), "como a argumentação visa obter a adesão daqueles a quem se dirige, ela é, por inteiro, relativa ao auditório que procura influenciar".

Assim, para Perelman e Olbstrects-Tyteca (2014), essa proposta que o orador se propõe a defender é a tese. Esta pode ser considerada, segundo a concepção dos autores, como o eixo da argumentação, pois é a partir da tese que se quer defender que são mobilizadas as técnicas e os argumentos em busca da adesão. Isso sugere dizer que "o modo de organização e funcionamento do texto persuasivo implica a escolha de técnicas argumentativas que sejam elaboradas com recursos selecionados para cumprir com a especificidade da forma de interação que se projeta" (BESSA; OLIVEIRA, 2019, p. 63).

Dentre os gêneros da ordem do argumentar (SCHNEUWLY; DOLZ, 2004) que favorecem um trabalho focado na exploração de técnicas argumentativas, optamos por explorar, em nossa proposta de intervenção, a carta do leitor, gênero discursivo sobre o qual discorreremos a seguir.

\section{O gênero discursivo carta do leitor}

Considerando a perspectiva interacional, dialógica e discursiva do funcionamento da linguagem que seguimos aqui, entendemos a carta do leitor como um gênero discursivo com finalidades comunicativas variadas. Para Bezerra (2010), a carta do leitor pode ter finalidades como opinar, agradecer, reclamar, criticar, entre outras, e visa a uma interação entre leitor e revista ou jornal. Essa autora lembra, contudo, que a carta do leitor diz respeito a "um texto utilizado em situação de ausência de contato imediato entre remetente e destinatário" (BEZERRA, 2010, p. 228), já que se trata de correspondência que o leitor do jornal ou revista encaminha à redação como resposta a algum texto prévio que o veículo tenha publicado.

Pertencente à esfera jornalística, este gênero é geralmente publicado em espaço fixo de revistas e jornais e recebe denominações as mais variadas, tais como cartas, cartas à redação, carta do leitor, painel do leitor. Trata-se de um enunciado que, por sua especificidade, destinase ao público em geral, revelando, via de regra, um auditório amplo e diversificado.

De acordo com Rodrigues (2005), as condições de produção/recepção da carta do leitor são caracterizadas pelas particularidades do contexto, no caso, a esfera jornalística, a qual controla as interações, os saberes, o conteúdo que circulará nesse espaço de comunicação. 
Segundo a autora, ao selecionar o que vão expor, os jornais, por exemplo, já conferem um acento de valor àquele conteúdo, já abreviam o que deve circular naquele universo, o que deve ser lido.

Bezerra (2010), por sua vez, aponta que, além de demonstrar um contato com os fatos recentes da sociedade, o gênero carta do leitor apresenta outros aspetos interacionais. Dentre eles, ela cita acessibilidade, meios midiáticos impressos ou digitais (portanto, de fácil acesso), linguagem adequada ao interlocutor, argumentatividade instigante (que pode despertar no aluno/leitor a necessidade ou o desejo de contra-argumentar) e, principalmente, é uma forma concreta de uso da escrita com função social.

Convém destacarmos, por fim, que, dependendo do público para o qual está sendo direcionado, bem como do suporte, a carta do leitor pode apresentar uma estrutura composicional diferente. Para este estudo, tomamos como base a estrutura composicional conforme consta em estudo de Bezerra (2010), que compreende uma seção de contato, o núcleo da carta, considerando aqui introdução, desenvolvimento e conclusão do texto, e a seção de despedida.

Compreendendo que os gêneros são tipos relativamente estáveis, entendemos que essa estrutura composicional proposta por Bezerra não é dada como pronta e acabada. Ainda assim, acreditamos que ela pode ser tomada como um bom parâmetro para orientar o enfrentamento analítico de nosso corpus.

\section{Metodologia}

Em sintonia com as formulações bakhtinianas sobre a pesquisa em ciências humanas, podemos assumir que este trabalho se configura como uma investigação de natureza interpretativa e de abordagem qualitativa (AMORIM, 2004). Dialogamos aqui também com o que preconiza Cresweell (2007), para quem a pesquisa qualitativa tem base na realidade construída por indivíduos interagindo com seus mundos sociais. Compreendemos, assim, que, em pesquisas dessa natureza, interessa ao pesquisador a construção de significados/sentidos sobre seu objeto de estudo, que, segundo essa compreensão, se constitui de textos/enunciados concretos (AMORIM, 2004; GERALDI, 2012).

Isso posto, a análise empreendida nesta investigação contempla o exame de dois textos da ordem do argumentar produzidos por um aluno do $1^{\circ}$ ano do ensino médio de uma escola pública estadual da Paraíba, durante o primeiro semestre de 2018, por ocasião do desenvolvimento de um projeto de trabalho (HERNÀNDEZ; VENTURA, 2017). A análise apresentada aqui é, portanto, um recorte de um corpus maior constituído durante as atividades 
de uma pesquisa de mestrado desenvolvida no âmbito do Programa de Pós-Graduação em Ensino, da Universidade do Estado do Rio Grande do Norte/Campus de Pau dos Ferros.

Considerando o tipo de pesquisa interventiva realizada, recortamos, para esta investigação, dois textos (uma redação escolar, texto produzido antes da intervenção, e uma carta do leitor, produzida no final da intervenção como produto do projeto de trabalho que desenvolvemos), que são compreendidos como enunciados únicos e concretos e considerados na íntegra, para análise. Essa análise estará assentada na metodologia do cotejo de textos, conforme sustenta Geraldi (2012), para o desenvolvimento de pesquisas nos estudos da linguagem que assumem a perspectiva dos estudos bakhtinianos.

Cumpre-nos esclarecer que a redação escolar foi coletada durante o período de observação das aulas da professora de língua portuguesa, o que se deu, portanto, em momento anterior ao da implementação de nossa proposta de intervenção. Já a carta do leitor foi coletada durante a intervenção, quando os alunos foram instigados a produzirem esse tipo de enunciado como resposta a editorais de jornais trabalhados, previamente, em atividades de leitura e análise linguística. Nessas atividades, foram trabalhados três editoriais de jornais que versavam sobre a temática da cobrança de mensalidades em universidades públicas brasileiras.

Embora o projeto fosse direcionado para o trabalho com a produção escrita, a proposta de intervenção realizada exigiu um longo período de leituras para que os participantes se familiarizassem com características dos gêneros, melhorassem a leitura, a capacidade de crítica, assim como compreendessem a leitura e a escrita como atividades indissociáveis e ainda ampliassem a compreensão sobre essas atividades como práticas sociais.

Considerando as questões éticas em pesquisa com seres humanos, consideramos importante mencionar que, para a realização de nossa investigação, e, posterior, divulgação dos resultados, foram providenciados o Termo de Anuência da Instituição, Termo de Consentimento Livre e Esclarecido e Termo de Assentimento Livre e Esclarecido, que foram assinados pelos participantes, depois de terem sido devidamente informados sobre os procedimentos éticos inerentes ao fazer pesquisa e divulgá-la para a comunidade científica.

\section{A construção argumentativa do dizer do aluno na produção textual no ensino médio: da redação escolar à carta do leitor}

Nesta seção, concentramos nossa atenção na análise da construção argumentativa do dizer do aluno em atividades de escrita no ensino médio, considerando o cotejo da produção textual que ele produziu antes e depois do trabalho interventivo. Nossa análise está organizada da seguinte forma: num primeiro momento, concentramo-nos na análise da redação escolar 
produzida antes da intervenção, e, em seguida, da carta do leitor. Desse modo, esperamos poder, a partir da análise e do cotejo das duas produções, dimensionar reflexos de nossa intervenção no desempenho do aluno em relação à capacidade argumentativa.

Iniciamos a análise reproduzindo a redação escolar produzida pelo aluno. A temática proposta pela professora da disciplina Língua Portuguesa girou em torno do namoro.

Ter ou não ter namorado?

Na fase da juventude passamos por muitas experiências, algumas alegres outras nem tanto. Evidentemente, esta é a época do surgimento das paqueras, flertes e, consequentemente, o namoro. Claro que, os namoros da atualidade são muito diferentes comparados ao tempo de nossos avós. Hoje, para as pessoas mais importam as aparências do que o sentimento. Mas a questão é: "Por que namorar?" para ter um estado civil? Para não ter fama de encalhada? Para agradar alguém? Ou porque você realmente ama uma pessoa e quer tentar um relacionamento com ela?

Ao contrário do que muitos pensam, um namoro não é resumido em postar fotos sorridentes na internet declarando o quanto não conseguiram viver um sem o outro mas, na realidade, não conseguem dizer um "eu te amo" cara a cara. Para um namoro de verdade acontecer é preciso compromisso, fidelidade, a capacidade de compreender e enxergar o lado do outro e, principalmente, o amor.

Muitas pessoas se sentem sozinhas e rejeitadas pelo simples fato de não namorar. Outras, têm vergonha de admitir em uma roda de amigos que ainda não beijaram ou nunca namoraram. Mas eu pergunto: "Por que namorar apenas como um passatempo?". Assumir um relacionamento sério tem suas vantagens e desvantagens. Mas quando se namora apenas para satisfazer uma pessoa, você não estará enganando apenas o(a) seu namorado(a) mas estará enganando a si mesmo.

A melhor sensação que se pode ter é amar e ser correspondido. Então se você ainda não encontrou a pessoa certa não se preocupe. Um dia vai acontecer pois, para tudo tem o tempo certo. Ela vai aparecer quando você menos esperar e vai te amar da maneira que você merece.

Rosalie Langdon ${ }^{3}$

Cumpre-nos observar, inicialmente, que esta produção textual demonstra um caráter questionador logo no seu início, quando constatamos que a aluna/produtora, apropriando-se dos dizeres alheios, transforma o título do texto de apoio - "Ter ou não ter namorado", escrito por Artur da Távola - em uma pergunta. Além disso, o parágrafo introdutório é marcado por questionamentos e ecos de muitas vozes originárias de vários discursos que são disseminados socialmente, como, por exemplo, os discursos da mídia, da igreja, da família, sinalizando a presença da palavra do outrem em seu dizer (BAKHTIN, 2011). No momento em que a autora se refere à fase da juventude como a época do surgimento das paqueras, flertes e, consequentemente, o namoro, fica evidente que se trata de dizeres sobre o namoro, muito comuns nesses espaços sociais quando as pessoas, de um modo geral, se expressam sobre a vida na adolescência em nossos dias.

\footnotetext{
${ }^{3}$ Nome fictício dado pelo próprio autor/a do texto.
} 
Percebemos, na sequência, um argumento construído a partir de discursos proferidos por vozes sociais, quando a aluna/produtora reproduz a fala: os namoros da atualidade são muito diferentes comparados ao tempo de nossos avós. Temos, segundo Perelman e OlbstrectsTyteca (2014, p. 304), um argumento pragmático baseado na estrutura do real, em que "a verdade deve ser preconizada, por possuir um valor absoluto, independente”. Considerando que a escrita é de uma aluna de 14 anos, este é, possivelmente, um discurso que ecoa vozes de muitas pessoas do círculo de relações sociais mais próximas, o que também se constitui em um conhecimento a partir do senso comum.

Observamos, ainda no primeiro parágrafo, que a autora retoma a ideia do título do texto com uma tonalidade bastante provocativa, trazendo uma sequência de interrogações: "Por que namorar?" para ter um estado civil? Para não ter fama de encalhada? Para agradar alguém? Ou porque você realmente ama uma pessoa e quer tentar um relacionamento com ela? Todas essas interrogações apontam para uma construção de sentidos com tonalidade irônica, já que o propósito da autora é questionar os relacionamentos da atualidade, caracterizados, de acordo com ela, como carentes de sentido.

O posicionamento crítico da autora acerca dos relacionamentos reaparece no segundo parágrafo, no qual podemos perceber sua crítica à superficialidade dos namoros, mais especificamente quando ela destaca que um namoro não é resumido em postar fotos sorridentes na internet declarando o quanto não conseguiram viver um sem o outro. A autora traz, pois, para a construção argumentativa o que Perelman e Olbstrects-Tyteca (2014) chamam de construção de argumentos baseados na estrutura do real por ligações simbólicas, já que baseados na ordem social e cultural de uma época, no caso, as postagens nas redes sociais. Ela constrói o argumento do lugar de qualidade, apontado por Perelman e Olbstrects-Tyteca (2014, p. 100), como aquele que "aparece na argumentação quando se contesta a virtude do número". Em seguida, a autora descreve comportamentos e atitudes que acredita serem necessários para que o namoro aconteça: Para um namoro de verdade acontecer é preciso compromisso, fidelidade, a capacidade de compreender e enxergar o lado do outro e, principalmente, o amor. Desse modo, a autora dá continuidade à crítica feita à superficialidade e à falta de sentido nos relacionamentos de hoje.

Nesse contexto de valores, podemos dizer que se caracteriza uma argumentação com valoração conservadora, pois, como definem Perelman e Olbstrects-Tyteca (2014, p. 90), “as noções de fidelidade, de lealdade e de solidariedade, vinculadas a valores concretos, costumam caracterizar, aliás, a argumentação conservadora”. Podemos inferir que, na expressão destacada no excerto, fica marcado que a autora considera os namoros, daquelas pessoas que estão 
preocupadas em aparecer bem nas redes sociais, como relacionamentos que não são verdadeiros. Nesse caso, novamente, ela se reporta ao lugar argumentativo de qualidade.

Mais adiante, no terceiro parágrafo, a autora volta a questionar o namoro por modismo ou por satisfação ao meio social, fazendo uma crítica a algumas situações comuns aos adolescentes quando negam o fato de estarem sozinhos para não se sentirem excluídos ou para parecerem bem ou descolados e na moda. Vemos aí um diálogo com vozes sociais do seu contexto sociocultural, demarcando, mais uma vez, um dizer tecido por relações dialógicas (BAKHTIN, 2011) que não são explicitadas linguisticamente.

Para encerrar o texto, é apresentado, novamente, pela autora, um discurso claramente construído por um dizer que ecoa de uma voz social que não é explicitamente demarcada, quando ela afirma que A melhor sensação que se pode ter é amar e ser correspondido. Nesse momento, a autora constrói um argumento sustentado pelo senso comum, para, em seguida, apresentar uma conclusão em que estabelece um diálogo com vozes da esfera familiar e religiosa quanto à ideia de encontrar a pessoa certa, quando menciona que: [...] Ela vai aparecer quando você menos esperar e vai te amar da maneira que você merece. Assim, a autora acaba projetando uma conclusão em que se utiliza de argumentação de finalidade baseada no senso comum.

Considerando a redação escolar em seu todo e acabado, podemos dizer que a produção escrita da aluna apresenta um caráter relativamente questionador e instigante. $\mathrm{O}$ fato de a produtora refutar com ironias a falta de sentido que considera haver nos relacionamentos de hoje nos faz acreditar ser considerável o domínio do conteúdo, já que ela consegue desenvolver a temática de modo satisfatório. É possível dizer ainda que, ao se centrar sobretudo em discursos do senso comum, como estratégia de dizer para sustentar seu ponto de vista, a autora não demonstrou apresentar uma boa afinidade com as técnicas argumentativas, de modo que pudesse construir um dizer assentado em argumentos com maior poder de convencimento e persuasão.

Com base nessa leitura que construímos da produção inicial da autora e levando em conta o propósito de contribuir com a melhoria da produção textual dos alunos, planejamos o trabalho interventivo com foco no gênero carta de leitor. Como já sinalizado, a temática proposta para a produção desse gênero do discurso foi a cobrança de mensalidades em universidades públicas brasileiras, a qual foi explorada e discutida em atividades de leitura e análise textual de editorais de jornais, trabalhados em aulas anteriores, no decorrer da intervenção. Foi, portanto, como uma atividade de resposta aos editoriais trabalhados que 
solicitamos o posicionamento da produtora no gênero carta do leitor que trazemos a seguir e que analisaremos posteriormente.

18 de julho de 2018

Caríssimo editorialista do jornal O Globo,

Tive acesso à matéria publicada sobre a possibilidade de cobrança de taxa nas universidades públicas. Achei a matéria muito interessante. Gostei de terem abordado essa temática tão relevante para o jovem brasileiro.

O problema da falta de recursos do governo é um tema discutido frequentemente e agora uma das alternativas para a solução desta crise é a injusta cobrança de taxas no ensino superior. Compreendo a forma como este tema é abordado, entretanto, discordo com sua forma de argumentação, pois destaca o fato de que grande parte dos alunos que entram nas universidades públicas são[sic] de famílias com boa estrutura financeira, sem considerar que isso é uma evidência da desigualdade econômica no país, o que acarreta em desigualdade na educação e em vários outros setores.

A medida, de cobrar pelo ensino público superior, que está sendo colocada como meio para resolver a situação, pode acabar se tornando um problema ainda maior para os alunos de baixa condição financeira. Estes podem estar sendo privados do direito a uma formação superior, pois de acordo com Tatiana Roque, presidente da associação dos professores da UFRJ, uma parcela considerável de estudantes, não cotistas, possui uma renda familiar média inferior a 8 mil reais e cobrar uma mensalidade de 2 mil significa excluir essas pessoas.

$O$ debate sobre este problema é de grande importância para a sociedade brasileira. É preciso que ele gere reflexões, tanto na mente dos nossos governantes quanto na da população. $\mathrm{Na}$ verdade, a população deveria tomar como exemplo a revolução dos "pinguins", acontecida no Chile, e exigir que na educação brasileira haja progresso, e não regresso.

Deve-se buscar outras alternativas para solucionar esta crise fiscal, como por exemplo, rever os gastos desnecessários feitos pelo governo em outros setores e extrair por outros meios, que não seja sacrificando ainda mais a população, para arcar com os investimentos na educação.

Cordialmente,

Rosalie Langdon

Podemos observar que, logo no começo da produção, a apresentação da temática já destaca a relevância do assunto para o jovem brasileiro, demonstrando que a autora da carta produzida concorda com o jornal em relação à escolha do tema para o debate. Porém, não é sinalizado aí, de forma explícita e precisa, o posicionamento da autora em relação a esse debate, já que ela apenas mostra que responde ao editorial do jornal $O$ Globo. Um posicionamento da autora da carta sobre a temática em questão vai aparecer expresso no parágrafo seguinte, quando ela considera a alternativa de cobrar mensalidades na universidade pública como uma medida “injusta", deixando claro, assim, sua oposição à defesa feita no editorial, e apontando, desse modo, a tese que ela pretende defender.

Considerando o enunciado na perspectiva dos estudos bakhtinianos, em que o dizer já pressupõe posição valorativa, entendemos que, nesse enunciado, a autora expressa uma posição 
em defesa da continuidade da gratuidade do ensino superior. Nesse sentido, procura realçar a negação à posição defendida pelo editorial, articulando, por conseguinte, um dizer que indica o sentido de "injustiça" se as universidades vierem a cobrar mensalidades.

No terceiro parágrafo, a autora da carta dialoga com o editorial dizendo que compreende a posição assumida pelo jornal, deixando, assim, transparecer que concorda com as informações sobre a participação da população mais carente nas universidades. Porém, ela discorda da omissão do editorial em relação a outros fatores que dificultam a acessibilidade desses alunos, como a desigualdade econômica, por exemplo, que tem efetiva colaboração nesses resultados e que poderia ser considerada nessa avaliação sugerida pelo editorial. Nesse momento, pode-se dizer que a autora confronta vozes e ideias expressas no editorial com o qual ela dialoga, estabelecendo um embate de vozes e desenvolvendo uma tensa luta dialógica (BAKHTIN, 2011) com as palavras do editorialista.

Na sequência, para sustentar sua tese, a autora busca reforçar seus argumentos lançando mão do recurso da voz de outrem (BAKHTIN, 2011), mobilizando, assim, um discurso de autoridade em defesa da gratuidade do ensino universitário, quando se reporta à professora Tatiana Roque 4 . A posição da professora da UFRJ, ao se referir a uma parcela de estudantes (no caso os não cotistas) que não suportaria a cobrança de mensalidade, é reportada para sustentar o ponto de vista defendido pela autora da carta, quando diz que [...] uma parcela considerável de estudantes, não cotistas, possui uma renda familiar média inferior a 8 mil reais e cobrar uma mensalidade de 2 mil significa excluir essas pessoas.

Ao trazer a voz de uma autoridade no assunto para a construção do texto, a autora da carta reforça seu posicionamento de considerar injusto cobrar mensalidades pelo ensino superior. Desse modo, ela organiza o seu dizer recorrendo a um argumento baseado na estrutura do real, o qual ajuda a fortalecer sua argumentação com a estratégia quase lógica construída com base em um argumento fundado na lógica quantitativa. Conforme Perelman e OlbrechtsTyteca (2014), essa estratégia de argumentação se manifesta quando há avaliações voltadas para a importância dos acontecimentos e da "esperança matemática".

No quinto parágrafo, a autora recorre a uma construção argumentativa por ligações que fundamentam a estrutura do real mediante o uso do recurso ao caso particular. Isso ocorre quando ela faz referência à revolução dos "pinguins", movimento de estudantes do Chile, iniciado em 2006, e que mobilizou a população por melhorias no sistema educacional e pela

\footnotetext{
${ }^{4}$ Durante o trabalho de produção escrita dos alunos, há várias recorrências ao texto "Quem paga o pato?”, de Tatiana Roque, professora da UFRJ, um dos textos utilizados como apoio para as leituras em sala de aula. Este texto está disponível em: https://oglobo.globo.com/opiniao/quem-paga-pato-19814254. Acesso em: 29 abr. 2018.
} 
anulação de um modelo de educação idealizado durante a autocracia do ditador chileno Augusto Pinochet. Tomando como "exemplo" esse acontecimento do Chile, a autora firma a compreensão de que a população deveria exigir progresso, e não regresso.

Embora a autora da carta tenha feito a opção por usar a palavra exemplo, compreendemos que as ligações que melhor definem o posicionamento sejam o modelo, que é apontado por Perelman e Olbrechts-Tyteca (2014) como um recurso de caso particular que incentiva a imitação e a ilustração, cuja finalidade é impressionar a imaginação e reforçar a adesão. Essa escolha estratégica da autora também aponta uma tomada de posição muito enfática, quando menciona as palavras progresso, e não regresso, expressando, desse modo, um sentido de provocação. Podemos dizer, ademais, que ela dialoga com as vozes das ruas, dos movimentos sociais, das lutas por cidadania e, principalmente, com o contexto vivenciado no Brasil, nos últimos quatro anos, de militância das classes trabalhadoras.

Na conclusão de sua carta, a autora tenta apresentar uma solução para a questão que vem discutindo no decorrer de seu texto, quando sugere [...] rever os gastos desnecessários feitos pelo governo em outros setores como alternativa para solucionar o problema de falta de verba para o ensino superior. Assim, observamos, mais uma vez, um dizer construído por meio de muitas vozes sociais que circulam no contexto atual, indicando a relação que toda produção discursiva tem com seu espaço-tempo (BAKHTIN, 2011)

Embora a autora sugira, na tessitura do dizer em sua carta, que os investimentos na educação ocorram sem que seja necessário privar a população mais pobre de serviços em outros setores, ela faz uma escolha linguística que deixa explicitada a presença e a força do discurso da mídia em relação à educação, quando usa a palavra "arcar". Como podemos depreender, tal palavra, no contexto em que é usada, indica o sentido de despesa e não de investimento na educação. A opção por essa palavra resulta, possivelmente, de diálogos com os discursos de certa parcela da mídia brasileira, que dissemina esse posicionamento na tentativa de persuadir o interlocutor quanto à defesa da cobrança de mensalidades no ensino público superior.

Essa leitura permite depreender que, na tessitura da carta, a autora conseguiu realizar uma discussão coerente com a temática em debate, construída de forma consistente e bem articulada, estabelecendo, inclusive, um diálogo pertinente e produtivo com posições do editorialista e de outras autoridades citadas. Isso mostra, portanto, que a autora organiza seu texto com encadeamento de ideias e articulando vozes e técnicas argumentativas que sustentam sua tese e colaboram para o convencimento do interlocutor.

Assim, podemos dizer que o domínio da estrutura composicional e do conteúdo expresso e a articulação das ideias, revelados na segunda produção demonstra, quando comparada com 
a produção inicial, que a aluna conseguiu potencializar sua capacidade argumentativa. Isso porque, como demonstramos nessa análise, fica evidente a construção de um dizer que expressa um posicionamento claro, que articula ideias e escolhas linguísticas de modo mais satisfatório e convincente e que corrobora para a intenção comunicativa da produtora.

\section{Conclusão}

Neste trabalho, propomo-nos a apresentar resultados de uma proposta de intervenção por meio da qual tivemos como finalidade trabalhar a produção textual em sala de aula do ensino médio, em uma perspectiva que buscasse articular aspectos da argumentação às formas de manifestações do discurso do outro como estratégia textual e discursiva. Nesse sentido, apresentamos aqui uma análise da construção argumentativa do dizer na produção textual de um aluno, considerando o cotejo das suas produções, antes e depois do trabalho interventivo.

Reportando-nos a pressupostos centrais da abordagem dialógica da linguagem bakhtiniana e da argumentação no discurso da Nova Retórica, realizamos uma análise de dois textos (uma redação escolar, texto produzido antes da intervenção, e uma carta do leitor, produzida no final da intervenção como produto do projeto de trabalho que desenvolvemos), compreendidos como enunciados únicos e concretos.

O estudo empreendido aponta que, quando analisamos e cotejamos a redação escolar e a carta do leitor, é possível perceber que o autor demonstrou um aprimoramento de sua capacidade argumentativa, uma vez que pudemos observar, na produção final, uma diversificação na mobilização de técnicas argumentativas selecionadas para sustentar os argumentos projetados com vistas a persuadir o interlocutor. Acrescentemos a isso que a mobilização de argumentos baseados na estrutura do real, bem como a recorrência a vozes que são reconhecidas como autoridade no assunto e a dados numéricos, dando sustentabilidade ao dizer, são aspectos que aparecem na produção da carta do leitor como resultado do aprimoramento na capacidade de argumentar do produtor após o trabalho de intervenção.

A análise aponta, por fim, que, ao final do trabalho interventivo, o aluno produziu um texto que apresenta posicionamentos críticos, fundados em técnicas argumentativas convincentes e consistentes, que satisfazem as finalidades comunicativas do seu produtor. Por isso, reforçamos a importância da atividade interventiva, centrada no gênero carta de leitor, como proposta de trabalho capaz de potencializar a capacidade argumentativa do aluno na produção de textos em sala de aula da educação básica. 


\section{Referências}

AMORIM, M. O pesquisador e seu outro: Bakhtin nas ciências humanas. São Paulo: Musa editora, 2004.

ANTUNES, I. Língua, texto e ensino: outra escola possível. São Paulo: Parábola Editorial, 2009.

ANTUNES, I. Aula de português: encontro \& interação. São Paulo: Parábola Editorial, 2003.

AZEVEDO, I. C. A construção do discurso argumentativo em perspectiva foucaultiana. Linha D'Água, v. 29, n. 2, p. 247-269, 2016.

BAKHTIN, M. Os gêneros do discurso. In: BAKHTIN, M. Os gêneros do discurso. Organização, tradução, posfácio e notas de Paulo Bezerra. São Paulo: Editora 34, 2016. p. 1169.

BAKHTIN, M. O texto na linguística, na filologia e em outras ciências humanas. In: BAKHTIN, M. Os gêneros do discurso. Organização, tradução, posfácio e notas de Paulo Bezerra. São Paulo: Editora 34, 2016. p. 71-107.

BAKHTIN, M. Problemas da poética de Dostoiévski. Trad. Paulo Bezerra. 5. ed. Rio de Janeiro: Forense Universitária, 2015.

BAKHTIN, M. Refromulação do livro sobre Dostoiévski. In: BAKHTIN, M. Estética da criação verbal. Introdução e tradução do russo Paulo Bezerra. São Paulo: Editora WMF Martins Fontes, 2011. p. 337-357.

BESSA, J. C. R. Dialogismo e construção da voz autoral na escrita do texto científico de jovens pesquisadores. 2016, 385 f. Tese (Doutorado em Linguística e Língua Portuguesa) Universidade Estadual Paulista "Júlio de Mesquita Filho", Faculdade de Ciências e Letras, Araraquara, 2016.

BESSA, J. C. R.; OLIVEIRA, J. A. A construção discursiva sobre o ensino superior público em editoriais de jornais de referência no Brasil. Revista Iberoamericana de Educación, v. 79, p. 59-79, 2019.

BEZERRA, M. A. Ensino de língua portuguesa e contextos teóricos- metodológicos. In: DIONISIO, A. P; MACHADO, A. R; BEZERRA, M. A. (Org.). Gêneros textuais \& ensino. São Paulo: Parábola Editorial, 2010. p. 39-50.

COSCARELLI, C. V. Perspectivas culturais de uso de tecnologias digitais e educação. Revista Brasileira de Alfabetização, v. 8, p. 33-56, 2019.

CRESWELL, J. W. Projeto de pesquisa: métodos qualitativo, quantitativo e misto. Trad. Oliveira da Rocha. 2. ed. Porto Alegre: Artmed, 2007.

DANTAS, S. G. M.; LIMA, S. DE C. A escrita colaborativa no Google Docs: uma proposta de ensino do gênero textual factual recount no ensino técnico de nível médio integrado.

Diálogo da Letras, v. 8, n. 3, p. 157-176, dez. 2019. 
FIORIN, J. L. Argumentação. São Paulo: Contexto. 2016.

GERALDI, J. W. Heterocientificidade nos estudos linguísticos. In: Grupo de Estudos dos Gêneros do Discurso - GEGe - UFSCar. Palavras e contrapalavras - enfrentando questões de metodologia bakhtiniana. São Carlos: Pedro \& João Editores, 2012. p. 19-39.

HERNÁNDEZ, F; VENTURA, M. A organização do currículo por projetos de trabalho: o conhecimento é um caleidoscópio. Trad. Jussara Haubert Rodrigues. 5. ed. Porto Alegre: Penso, 2017.

KERSCH, D. F.; MARQUES, R. G. Redes sociais digitais na escola: possibilidades de conexão, produção de sentido e aprendizagem. Diálogo das Letras, Pau dos Ferros, v. 6, n. 2, p. 343-362, jul./dez. 2017.

LOPES-ROSSI. M. A. G. Práticas de leitura de gêneros discursivos: a reportagem como proposta. In: PETRONI. M. R. (Org). Gêneros do discurso, leitura e escrita: experiências de sala de aula. São Carlos: Pedro \& João Editores. Cuiabá: EdUFMT, 2008. p. 51-68.

MENDONÇA, M. C. A produção textual na esfera escolar: considerações sobre a "escrita como trabalho". Diálogo das Letras, Pau dos Ferros, v. 8, n. 1, p. 3-15, jan./abr. 2019.

MORETTO, M. Produção de textos em sala de aula: momento de interação e diálogo. Jundiaí: Paco editorial, 2013.

NASCIMENTO, E. P. Gêneros jornalísticos na sala de aula: desenvolvendo habilidades leitoras. In: PEREIRA, R. C. M. (Org.). Ações de linguagem: da formação continuada à sala de aula. João Pessoa. Editora Universitária da UFPB, 2010. p. 56-87.

NASCIMENTO, E. P.; ARAUJO, A. L. R. B. Produção textual do gênero artigo de opinião no ensino fundamental: uma proposta de ensino e aprendizagem mediada por sequências didáticas. Leia Escola, v. 15, n. 2, p. 71-83, 2015.

OLIVEIRA, J. A. Produção textual argumentativa na sala de aula: do editorial à carta do leitor. 2019, 179 f. Dissertação (Mestrado em Ensino) - Universidade do Estado do Rio Grande do Norte, Campus de Pau dos Ferros, Pau dos Ferros, 2019.

PERELMAN, C; OLBRECHTS-TYTECA, L. Tratado de argumentação: a nova retórica. Trad. M. E. A. P. Galvão. São Paulo: Martins Fontes, 2014.

RIBEIRO, A. E. Que futuros redesenhamos? Uma releitura do manifesto da Pedagogia dos Multiletramentos e seus ecos no Brasil para o século XXI. Diálogo da Letras, v. 9, e02011, p. 1-19,2020.

RIBEIRO, A. E. Escrever hoje: palavra, imagem e tecnologias digitais na educação. São Paulo: Parábola, 2018.

RODRIGUES, R. H. Os gêneros do discurso na perspectiva dialógica da linguagem: a abordagem do Círculo de Bakhtin. In: MEURER, J. L.; BONINI, A.; MOTTA-ROTH, D. (Org.). Gêneros: teorias, métodos, debates. São Paulo: Parábola, 2005. 152-183. 
SCHNEUWLY, B.; DOLZ, J. Gêneros orais e escritos na escola. Trad. Roxane Rojo e Glaís Sales Cordeiro. Campinas: Mercado das Letras, 2004

SOUZA, G. S. Argumentação no discurso: questões conceituais. In: FREITAS, A. C.; RODRIGUES, L. R.; SAMPAIO, M. L. Linguagem, discurso, cultura: múltiplos objetos e abordagens. Pau dos Ferros: Queima-bucha, 2008.

VOLÓCHINOV, V. Marxismo e filosofia da linguagem: problemas fundamentais do método sociológico na ciência da linguagem. Trad. Sheila Grillo e Ekaterina Vólkova. São Paulo: Editora 34, 2017.

\section{Sobre os autores}

Joseilda Alves de Oliveira (Orcid iD: https://orcid.org/0000-0003-1403-0342)

Doutoranda no Programa de Pós-Graduação em Letras da Universidade do Estado do Rio Grande do Norte (UERN); mestra em Ensino pela mesma instituição; especialista em Educação de Jovens e Adultos e Economia Solidária pela Universidade Federal de Campina Grande (UFCG) e em Língua, Linguística e Literatura pelas Faculdades Integradas de Patos; graduada em Pedagogia pela Universidade Paulista e em Letras - Português/Inglês pelas Faculdades Integradas de Patos. É professora da Educação Básica vinculada às secretarias municipais de Educação de CondadoPB e Malta-PB.

José Cezinaldo Rocha Bessa (Orcid iD: https://orcid.org/0000-0003-4655-6832)

Doutor em Linguística e Língua Portuguesa pela Universidade Estadual Paulista Júlio de Mesquita Filho (UNESP), Araraquara; mestre em Estudos da Linguagem pela Universidade Federal do Rio Grande do Norte (UFRN); graduado em Letras - Língua Portuguesa e respectivas literaturas pela Universidade do Estado do Rio Grande do Norte (UERN). É professor dos cursos de graduação em Letras, do Programa de Pós-Graduação em Letras e do Programa de PósGraduação em Ensino da UERN.

Recebido em agosto de 2020.

Aprovado em dezembro de 2020. 